\title{
POTENCIAL EVOCADO AUDITIVO NO CÓRTEX DO BICHO PREGUIÇA
}

\author{
J. LacaZ DE MoRaes * \\ F. LACAZ VIEIRA ** \\ S. MALHEIRos Lopes ***
}

$\mathrm{Na}$ literatura especializada a nosso alcance não encontramos trabalho referente à localização de áreas sensoriais nos xenartras, utilizando métodos eletrofisiológicos.

\section{MATERIAL E METODOS}

Foram utilizados 13 animais adultos, de ambos os sexos, com pêso de 2 a 5 quilos, anestesiados com pentobarbital sódico, na dose de $50 \mathrm{mg}$ por quilo de pêso, ou cloralose (isômero alfa), na dose de 50 a $70 \mathrm{mg}$ por quilo de pêso. Estes anestésicos eram ministrados por meio de uma cânula de polietileno introduzida na veia jugular direita. A colocação da cânula era feita sob anestesia local por escurocaina, solução a 1\%. Doses de manutenção de pentobarbital ou cloralose foram ministradas sempre que a atividade cortical espontânea dificultava o registro da resposta evocada. Os animais eram curarizados por Flaxedil, em dose suficiente para produzir apnéia. A respiraçāo era mantida por uma bomba de pressão positiva.

Após craniotomia ampla e exposição de grande parte do hemisfério esquerdo, era aberta a dura máter, sendo o córtex banhado com óleo mineral neutro, aquecido à temperatura do corpo do animal. Para a derivação cortical foram usados eletródios de prata cloretada ( $\mathrm{Ag}-\mathrm{AgCl}$ ), de platína ou de aço inoxidável. O eletródio indiferente, ligado à terra, era prêso num dos lábios da ferida operatória. A amplificação da atividade elétrica cortical era feita por pré-amplificador Grass P-5, em coneç̧ão com um oscilógrafo catódico Dumont, de duplo feixe, de onde era feito o registro fotográfico.

A estimulação acústica era feita pelo som de um alto falante, ligado a amplificador comandado por estimulador Grass S-4. O som produzido era um "clic", cuja intensidade e freqüência podiam ser variadas pelos contrôles do estimulador. A estimulação era biauricular, com o alto falante colocado à frente da cabeça do animal. Foram tomadas precauções para se evitar que vibrações mecânicas, provenientes do alto falante, chegassem ao corpo do animal. Como fonte de som contínuo foi usado um oscilador de onda sinusoidal, de frequiencia e intensidade variáveis. O mapeamento era feito deslocando-se o eletródio sôbre a superfície

Trabalho do Departamento de Fisiologia da Faculdade de Medicina da Universidade de São Paulo (Prof. Alberto Carvalho da Silva, Catedrático interino): * Professor Assistente; ** Monitor e bolsista da F.A.P.E.S.P.; *** Biologista.

Nota dos autores - Agradecemos ao Dr. Eros Abrantes Erhart e Dr. Alberto Carvalho da Silva, pelas sugestōes na redação, assim como ao Sr. Edilson Branco, que nos facilitou a aquisição de diversos animais. 
do córtex, de milimetro em milimetro, em relação aos eixos ântero-posterior e lateral da cabeça do animal. As referênclas de anatomia macroscópica do encéfalo da preguiça (Bradypus tridactylus) basearam-se em Elliot-Smith ${ }^{4}$ e Anthony ${ }^{2}$.

\section{RESULTADOS}

De modo geral, foram encontrados dois tipos de respostas quanto à localização no córtex cerebral: o primeiro, de distribuição localizada, abaixo do sulco supra-silviano; o segundo, de distribuição difusa, com predominio no pólo anterior. As respostas localizadas podem ser agrupadas, quanto à latência, em respostas de curta, média e longa latência.

Respostas localizadas de curta latência. - O foco de respostas de curta latência está situado imediatamente abaixo da porção média do sulco supra-silviano, como mostra a figura 1. A extensão dêste foco varia de animal para animal, conforme o estado de excitabilidade cortical. Pode-se encontrar, em alguns animais, o foco de curta latência restrito a uma zona puntiforme, ao passo que, em outros, a extensão do mesmo pode chegar a $5 \mathrm{~mm}$ de diâmetro. Nestes casos de excitabilidade cortical intensa, encontrou-se resposta de curta latência acima do sulco supra-silviano, sendo, porém, de amplitude bem reduzida em relaçāo às respostas encontradas abaixo do referido sulco. A redução da amplitude, ao se cruzar êste sulco de baixo para cima, sofre um degrau, fato que não se verifica,

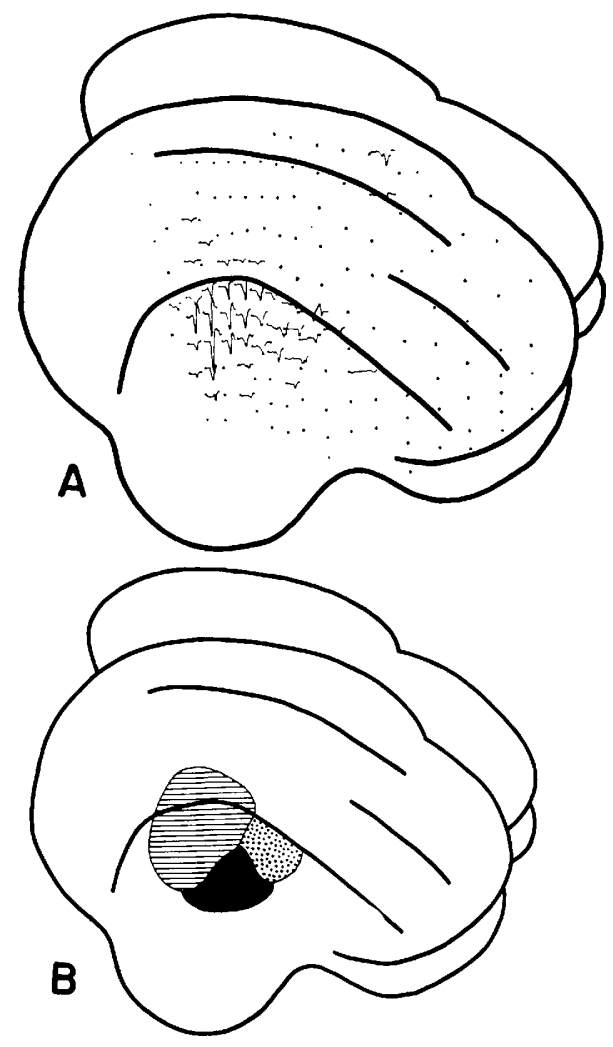

Fig. 1 - Em A, representação das respostas evocadas mediante estimulo auditivo no hemisfério direito de um dos animais (anestesia por cloralose). Em B, representacão esquemática das áreas ativas mostradas em A; em traços, região onde ocorreram respostas de curta latência; em prêto, região de média latência; em pontilhado, região de longa latência. Foram assinaladas, também, pequenas respostas acima do sulco supra-silviano. 
ao se estudar a diminuiçāo de amplitude das respostas, quando se caminha em outras direções a partir do centro dêste foco (fig. 1). A latência das respostas, nesta região, é de $20 \mathrm{~ms}$ (19 a $25 \mathrm{~ms}$ ) para o início da fase positiva e de $30 \mathrm{~ms}$ (27 a $35 \mathrm{~ms}$ ) para o pico positivo, como valôres médios. Na periferia do foco foram encontradas respostas com latências maiores, chegando até $25 \mathrm{~ms}$ para o inicio; raramente encontramos respostas com latência abaixo de $20 \mathrm{~ms}$ e, nunca, inferiores a $19 \mathrm{~ms}$. Estes valôres são idênticos quer seja usada a cloralose ou barbitúricos como anestésicos. O ciclo de recuperação do foco de curta latência foi estudado pela técnica dos dois estímulos sucessivos, sendo de 5 segundos o intervalo entre cada par de estímulos (fig. 2). Só estudamos êste ciclo sob anestesia barbitúrica.

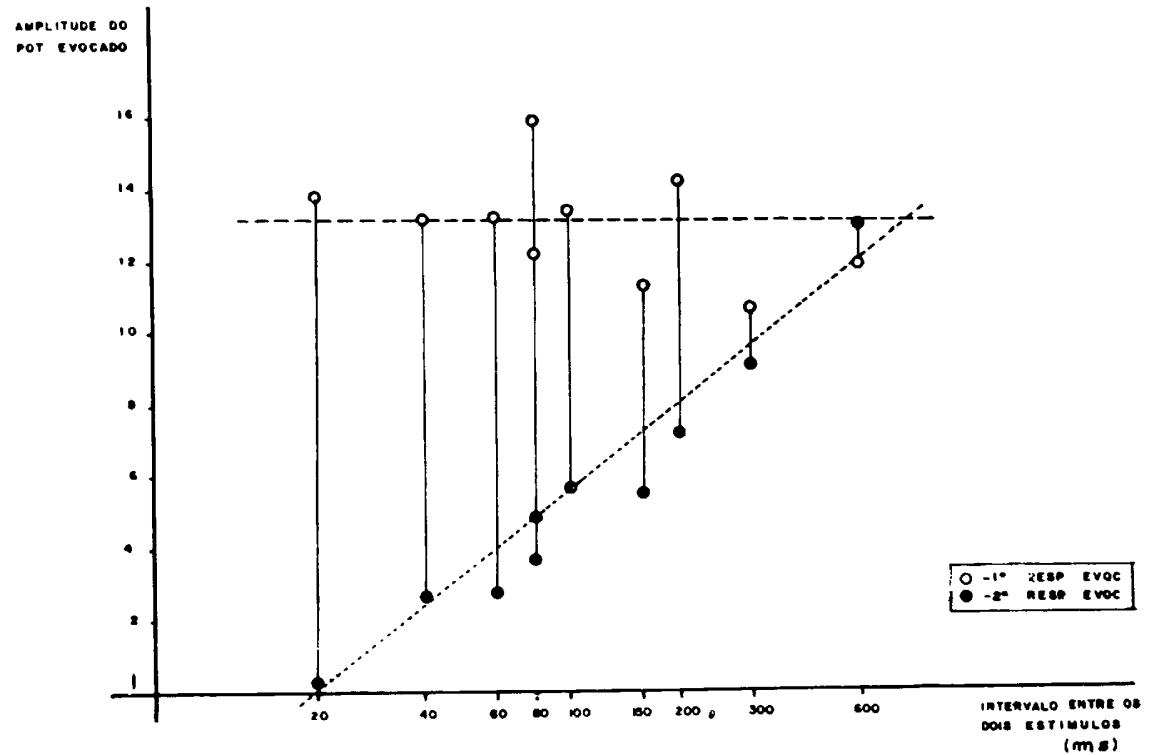

Fig. 2 - Amplitude das respostas em unidades arbitrárias. Gráfico do ciclo de recuperação em área de curta latência. Cada ponto do gráfico corresponde à média das amplitudes de 20 respostas evocadas, tanto para o primeiro como para o segundo estimulo. No intervalo de $80 \mathrm{~ms}$ foi dada uma dose de manutenção de Nembuta?: como resultado, houve redução da amplitude média das respostas ao primeiro e ao segundo estimulos. Anestesia por Nembutal.

Respostas localizadas de média latência $\rightarrow \mathrm{O}$ foco de respostas de média latência, situado abaixo e à frente do foco de curta latência (fig. 1), apresenta variações em sua extensão, de animal para animal. E mais dificilmente ativado que o de curta latência, e, em algumas preparações, não foi possivel individualizá-lo. Aparece tanto com anestesia cloralósica como barbitúrica. Neste foco, a latência das respostas é em média de $30 \mathrm{~ms}(27$ a $35 \mathrm{~ms})$ para o início da fase positiva e de $40 \mathrm{~ms}$ (32 a $45 \mathrm{~ms}$ ) para o pico positivo. O ciclo de recuperaçāo não foi estudado para êste foco.

Respostas localizadas de longa latência - Estas respostas serão estudadas juntamente com as respostas difusas. 
Respostas difusas - Em alguns animais encontramos respostas auditivas de longa latência distribuídas difusamente no córtex, com predominância no pólo anterior (fig. 3). Este tipo de resposta é mais favoràvelmente obtido com a anestesia barbitúrica, porém, aparece como resposta de pequena amplitude, com anestesia cloralósica. Em um dos animais encontramos, com cloralose, um foco de longa latência situado abaixo do sulco supra-silviano e mais frontalmente ao foco de média latência, como se vê na figura 1. As respostas de longa latência, comparativamente com as de média e curta, apresentam grande instabilidade em sua amplitude. A latência para o início da fase positiva varia de 50 a $95 \mathrm{~ms}$, predominando as respostas de 50 a $70 \mathrm{~ms}$. O pico positivo se encontra afastado geralmente de $15 \mathrm{~ms}$ do início da fase positiva. Não foi estudado o ciclo de recuperação.

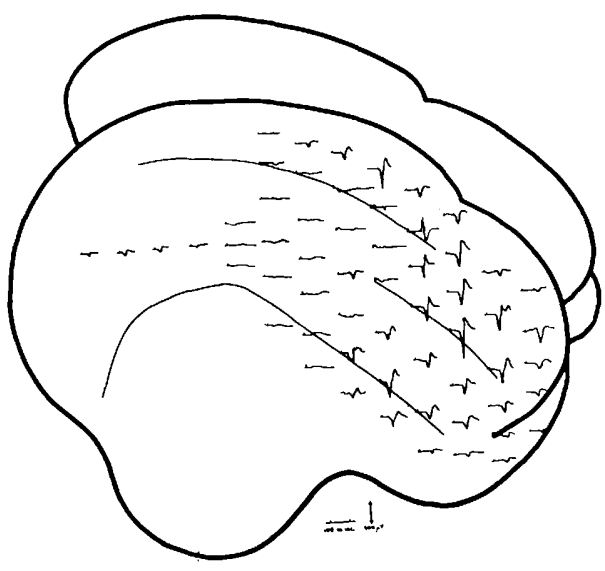

Fig. 3 - Resposta de longa latência, de distribuiça difusa, com predominio no pólo anterior do cérebro. Anestesia barbitúrica.

Influência de um som continuo sôbre a resposta evocada por "clic" em área de curta latência - Quando juntamente com os "clics" emite-se um som continuo, verifica-se (fig. 4): 1) uma fase de bloqueio total das respostas evocadas, durante a vigência do som contínuo; 2) uma fase de bloqueio parcial, que se segue à primeira, também durante a vigência do som contínuo, na qual há escape de algumas respostas evocadas; 3) cessando o som continuo, segue-se uma fase de exaltação das respostas evocadas, de tempo variável, ao cabo da qual a amplitude das respostas evocadas se normaliza. A fase de bloqueio total é tanto mais duradoura quanto mais intenso o som continuo. A medida que se diminui a intensidade dêste som, a fase de bloqueio total diminui em favor da de bloqueio parcial, que aumenta. Um som continuo, de determinada intensidade e frequiência, pode bloquear a resposta evocada em um ponto do córtex e ser ineficaz para outro ponto a alguns milímetros do primeiro, sendo preciso, para bloquear o mais refratário, intensidade sonora muito mais intensa.

Asfixia e atividade cortical evocada em área de curta latência — A asfixia foi produzida pela obstrução da traquéia, estando o animal prèviamente curarizado e com respiração artificial. Uma vez iniciada a asfixia e decorrido certo tempo, a amplitude do potencial evocado decresce, chegando $\bar{a}$ desaparecer totalmente com o progredir da mesma. Neste momento está abolida também a atividade cortical espontânea, quando a profundidade da anestesia já não a havia abolido. Restabelecendo a respiração artificial verifica-se o reaparecimento tanto da atividade evocada como da espontânea. Êste restabelecimento da atividade se faz progressivamente até que a amplitude das respostas volte aos valôres anteriores 


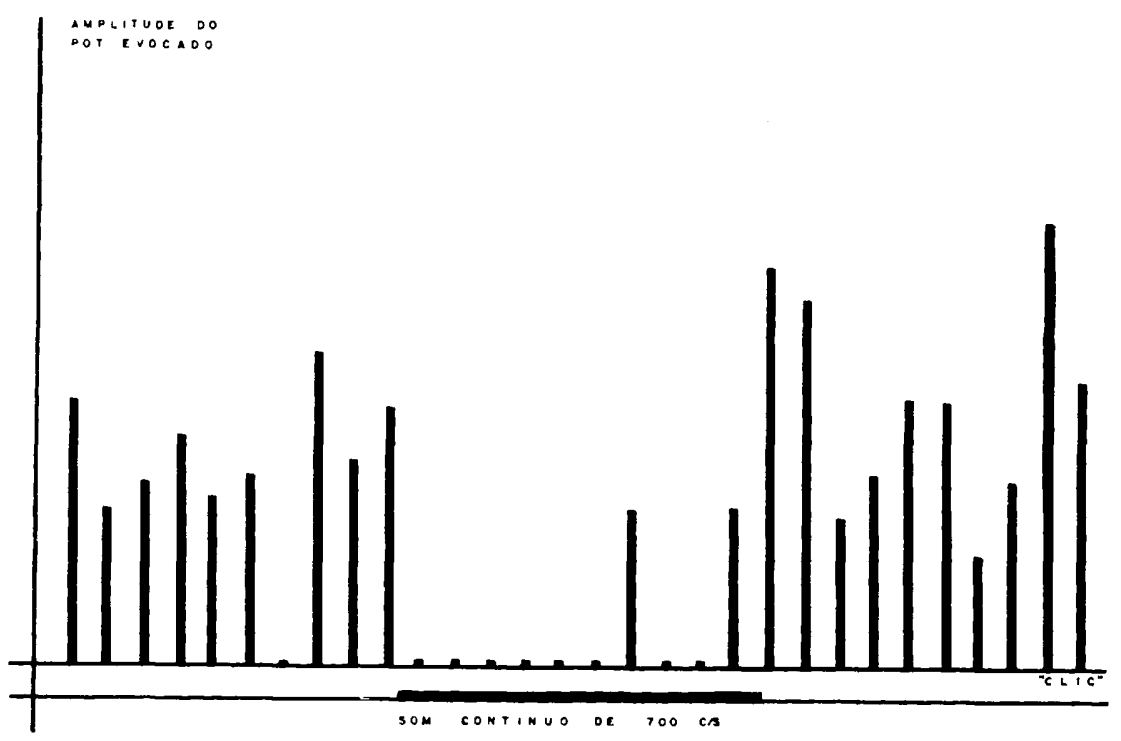

Fig. 4 - Influência de som continuo sôbre as respostas evocadas no córtex. $O$ intervalo entre os "clics" $\dot{e}$ de 10 segundos. Amplitude do potencial em unidades arbitrárias. Anestesia por cloralose, seguida de doses de manutenção de Nembutal.

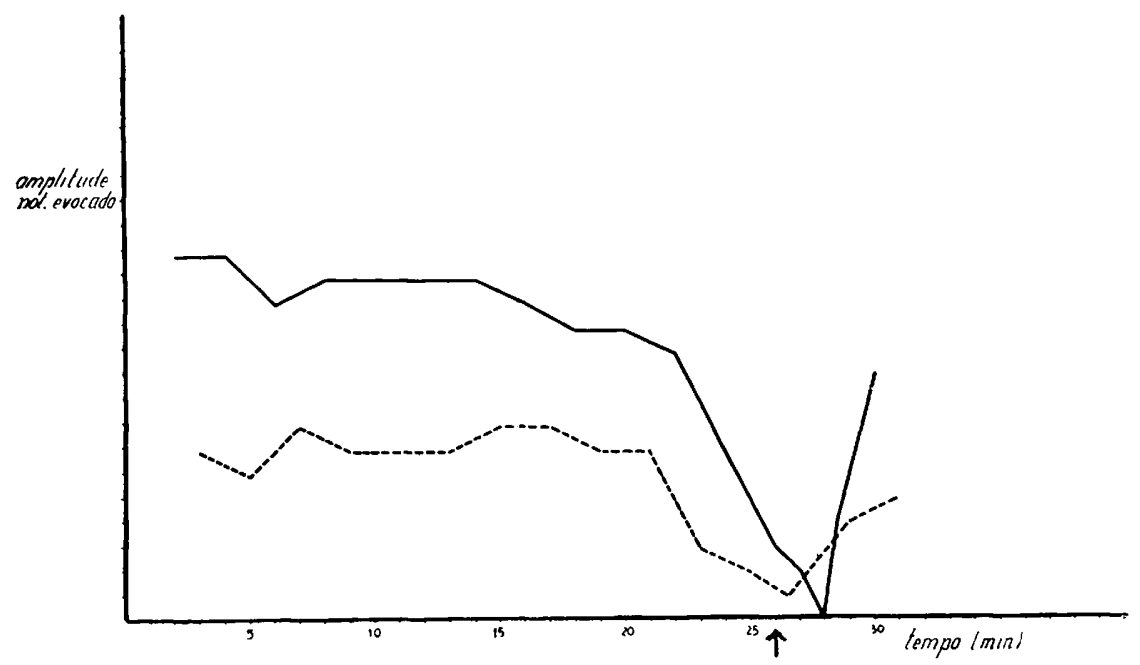

Fig. 5 - Asfixia e amplitude do potencial evocado em ârea de curta latência. Em traco cheio, o intervalo entre cada par de estimulos é de 5 segundos. Em traço interrompido o intervalo entre cada par de estimulos é de 0,5 segundos. $O$ tempo é contado a partir do infcio da asfixia. A flecha indica o retôrno da respiracão artificial. Anestesia por cloralose. 
à asfixia (fig. 6). Aumentando a freqüência dos "clics", verifica-se que a amplitude do potencial evocado diminui (vide ciclo de recuperação), porém, a extinção da resposta se faz ao mesmo tempo, tanto para estimulação com alta como com baixa freqüência (fig. 5).

A redução da amplitude da resposta evocada se faz simultâneamente para ambas as fases positiva e negativa da resposta ou com a predominância de uma delas. Assim, podemos ter nas fases finais da asfixia a persistência de uma resposta evocada mostrando-se somente positiva ou somente negativa (fig. 6). Quando da persistência da fase negativa, verifica-se que a sua latência é a mesma que a do componente negativo, quando a resposta era ainda positivanegativa.

A<smiles>CCCCCCCCC</smiles>

B

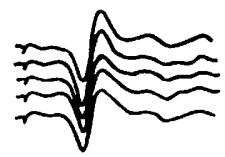

C

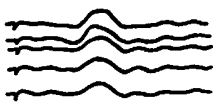

D

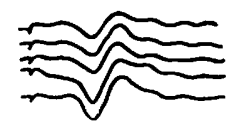

$E$

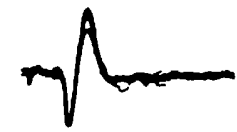

F

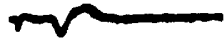

J

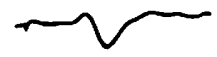

G

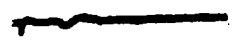

L

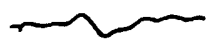

H
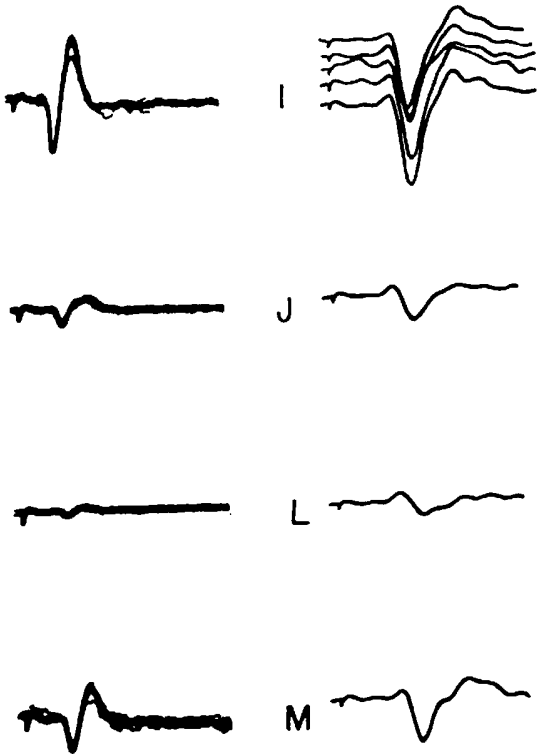
calização e conformaçāo muito parecidas. Na preguiça, assim como nos carnívoros, a área de projeção primária da audição encontra-se situada imediatamente abaixo do sulco supra-silviano.

Com os dados de latência, duração da fase positiva e estabilidade do fozo, podemos conjcturar a respeito de diferenças funcionais entre as regiões de curta e média latência. Comparando nossos resultados com os que foram obtidos no gato (Albe-Fessard 1; Bremer, Bonnet e Terzuolo ${ }^{3}$ ), pcdemos chamar a região de curta latência de A-I e a de média latência de A-II. Contudo, a latência das respostas em A-I, que na preguiça é de $20 \mathrm{~ms}$, difere nitidamente da encontrada no gato (A-I: $8 \mathrm{~ms}$; Albe-Fessard ${ }^{1}$ ) e no macaco (A-I; 7,5 ms; Pribram, Rosner, Rosenblith `).

A resposta de longa latência, de distribuição difusa, assemelha-se à resposta descrita por Forbes e Morison ". Neste trabalho visamos apenas descrever a ocorrência dêste tipo de resposta na preguiça mediante estimulação auditiva.

A discordância entre nossos resultados, em que não se verifica a existência da fase de amplitude reduzida, após a interrupção do som contínuo, e os de Rosenblith, Galambos, Hirsh ${ }^{8}$, no gato, talv $\in Z$ se deva ao fato de que o intervalo entre os "clics" era de 10 segundos; assim, o primeiro estímulo após a interrupção do som contínuo caia já no período de supernormalidade das respostas. Hawkins e Kniazuk ${ }^{6}$ mostraram que a recuperação da amplitude dos potenciais do nervo coclear após a interrupção do som contínuo é tanto mais demorada quanto maior a intensidade do som contínuo. Fato semelhante poderá existir para a resposta cortical, como conseqüência do que foi exposto acima, já que em nosso caso a intensidade do som contínuo era pouco acima da necessária para produzir bloqueio total. Isto favoreceria a ausência em nossos resultados da fase de amplitude reduzida.

O desaparecimento da fase positiva da resposta bifásica com persistência da negativa é um dado que fala a favor da fase negativa não ser devida, pelo menos exclusivamente, à ativação dos dendritos apicais das pirâmides, a partir de estimulos provenientes do corpo das mesmas. Provàvelmente a fase negativa é devida se não totalmente, pelo menos em parte, à atividade de células situadas mais superficialmente no córtex, e que são mais resistentes à asfixia. Von Euler e Ricci ${ }^{9}$, estudando a latência da fase negativa, quando faziam descer um eletródio a profundidades diferentes no córtex cerebral, aventaram a hipótese de ser insignificante o papel da rêde dendrítica apical na gênese da fase negativa.

\section{RESUMO}

Foram estudadas as respostas evocadas no córtex do bicho preguiça (Bradypus tridactylus) mediante estimulação auditiva, o que permitiu delimitar, abaixo do sulco supra-silviano, duas áreas auditivas (A-I e A-II), com latência para o início da fase positiva de $20 \mathrm{~ms}(19-25 \mathrm{~ms})$ e $30 \mathrm{~ms}$ (27-35 ms), respectivamente. Com anestesia barbitúrica profunda, foram 
obtidas respostas de longa latência $(65-110 \mathrm{~ms}$ para o início da fase positiva), distribuídas difusamente no córtex, com predominância no pólo anterior do cérebro. Foi estudada a interação de um som contínuo sôbre a resposta evocada em AI, assim como a resistência da resposta evocada em A-I à asfixia. Alguns animais apresentaram resposta evocada em A-I, mesmo após 25 minutos de asfixia.

\section{SUMMARY}

Evoked responses in auditory cortex of the sloth (Bradypus tridactylus).

The auditory cortex of the sloth was studied through evoked responses method with demonstration of two active areas beneath the supra-sylvian grouve. In A-I the latency of the beginning of the surface positive wave range from 19 to $25 \mathrm{~ms}$, predominantly $20 \mathrm{~ms}$, and in A-II, range from 27 to $35 \mathrm{~ms}$, predominantly $30 \mathrm{~ms}$. With deep barbiturate narcosis a long latency responses $(65-110 \mathrm{~ms}$ for the beginning of the surface positive wave) was observed spreading over the anterior pole cortex. Interaction of a continuous sound with the evoked responses in A-I was also investigated. Evoked responses in A-I cortex could be obtained after 25 minutes of asphyxia produced by obstruction of the trachea.

\section{REFERENCIAS}

1. ALBE-FESSARD, D. - Activités de projection et d'association du néocortex cérébral des mammifères. J. Physiológie, 49:521, 1957. 2. ANTHONY, J. - Morphologie externe du telencephale dans le genre Bradypus (Edentata). Mammalia, 17:149, 1953. 3. BREMER, F.; BONNET, V.; TERZUOLO, C. - Etude electrophysiologique des aires auditives eorticales du chat. Arch. Int. Physiol., 62:390, 1954. 4. ELLIOT-SMITH, G. - The brain in edentata. Trans. Linn. Soc. London, 7, pt 7, 277, 1899. 5. FORBES, A.; MORISON, B. R. - Cortical response to sensory stimulation under deep barbiturate narcosis. J. Neurophysiol., 2:112, 1939. 6. HAWKINS, Jr., J. E.; KNIAZUK, M. - The recovery of the auditory nerve action potencials after masking. Science, 111:567, 1956. 7. PRIBRAM, K. H.; ROSNER, B. S.; ROSENBLITH, W. A. - Electrical responses to acoustic clics in monkey: extent of neocortex activated. J. Neurophysiol., 17:336, 1954. 8. ROSENBLITH, W. A.; GALAMBOS, R.; HIRSH, I. J. - The effect of exposure to loud tones upon animal and human responses to acoustic clics. Science, 111:569, 1956. 9. von EULER, C.; RICCI, G. F. - Cortical evoked responses in auditory area and significance of apical dendrites. J. Neurophysiol., 21:231, 1958.

Departamento de Fisiologia. Faculdade de Medicina da Universidade de São Paulo - Caixa Postal 2921 - São Paulo, Brasil. 